\title{
Differences in the Phagocytic Response of Microglia and Peripheral Macrophages after Spinal Cord Injury and Its Effects on Cell Death
}

\author{
Andrew D. Greenhalgh and Samuel David \\ Centre for Research in Neuroscience, The Research Institute of the McGill University Health Center, Montreal, Quebec, Canada, H3G 1A4
}

\begin{abstract}
Macrophages in the injured spinal cord arise from resident microglia and infiltrating, peripherally derived monocytes. It is still not clear if macrophages derived from these two populations differ in their roles after CNS injury. The aims of this study are to investigate the phagocytic response and clearance of damaged axons and tissue debris by these distinct subsets of macrophages and assess their viability after spinal cord injury (SCI). The lysozyme M EGFP-knockin mouse tags hematogenous macrophages, but not microglia. Using a combination of immunofluorescence, flow cytometry, and neuronal tracing techniques, we show that microglia contact damaged axons early $(24 \mathrm{~h})$ after SCI and are the main type of macrophage to contain phagocytic material at $3 \mathrm{~d}$. Thereafter, infiltrating macrophages become the predominant cell in contact with degenerating axons and contain more phagocytic material, which in contrast to microglia, persists for up to $42 \mathrm{~d}$. Furthermore, after phagocytosis of myelin in vitro, bone marrow-derived macrophages are much more susceptible to apoptotic and necrotic cell death than CNS microglia, which is mirrored in vivo with apoptotic TUNEL-positive cells of infiltrating macrophage origin. This work suggests that microglia play a major role in the early response to SCI, by phagocytosing damaged and degenerating tissue, processing phagocytic material efficiently, and remaining viable. Later, macrophages of peripheral origin contribute predominantly to phagocytosis but are less efficient at processing CNS debris, and their death, in situ, may contribute to the secondary damage after CNS injury.
\end{abstract}

Key words: cell death; macrophage; microglia; phagocytosis; spinal cord injury

\section{Introduction}

The inflammatory response after spinal cord injury (SCI) has been widely targeted to improve outcome. Recently, there has been an intense focus on the role and phenotype of macrophages in SCI, particularly whether specific populations of macrophages contribute to excessive and detrimental inflammation or, conversely, beneficial repair (David and Kroner, 2011; Gensel et al., 2012; Shechter and Schwartz, 2013). However, the origin of macrophages within the injured spinal cord, and their subsequent fate, has received less attention. Macrophages at the site of CNS injury can arise from two ontogenetically distinct populations: resident microglia or circulating monocytes (Ginhoux et al., 2010; David and Kroner, 2011). Under normal conditions, microglia survey the CNS environment and respond to injury within minutes with process redirection and cell body migration

\footnotetext{
Received Nov. 22, 2013; revised Feb. 24, 2014; accepted March 26, 2014.

Author contributions: A.D.G. and S.D. designed research; A.D.G. performed research; A.D.G. analyzed data; A.D.G. and S.D. wrote the paper.

This work was supported by a grant from the Canadian Institutes of Health Research (CIHR; MOP-14828) to S.D., A.D.G. is supported by a CIHR Postdoctoral fellowship and also received support from the CIHR Neuroinflammation Training Program.

The authors declare no competing financial interests.

Correspondence should be addressed to Dr. Samuel David, Centre for Research in Neuroscience, The Research Institute of the McGill University Health Center, Livingston Hall, Room L7-210, 1650 Cedar Avenue, Montreal, Québec, Canada, H3G 1A4. E-mail: sam.david@mcgill.ca.

DOI:10.1523/JNEUROSCI.4912-13.2014

Copyright $\odot 2014$ the authors $\quad 0270-6474 / 14 / 346316-07 \$ 15.00 / 0$
}

(Davalos et al., 2005; Nimmerjahn et al., 2005). In the case of SCI, infiltrating macrophages from the peripheral circulation also enter the site of injury after $\sim 3 \mathrm{~d}$ (Popovich and Hickey, 2001; Mawhinney et al., 2012). Here the two cell types express many of the same immunohistochemical markers and are morphologically indistinguishable from each other, and are therefore often referred to as microglia/macrophages.

The phagocytic activity of macrophages within the CNS is thought to play an important role in recovery, maintenance, and outcome during disease or injury (Yong and Rivest, 2009). However, little is known about the phagocytic role and relative contribution of the distinct microglia and peripheral macrophage populations on degenerating axons and other neural tissue components, in vivo, after SCI. Furthermore, the important question of the viability of activated, phagocytic microglia and macrophage populations in the injured spinal cord has not been addressed.

In the present study, we used the lysozyme M EGFP-knockin (lys-EGFP-ki) mouse, which drives the expression of EGFP specifically in mature myelomonocytic cells, but not microglia (Faust et al., 2000). The lys-EGFP-ki mouse has been used to distinguish resident microglia from infiltrating macrophages in models of CNS infection (Howe et al., 2012), experimental autoimmune encephalomyelitis (EAE; Oweida et al., 2007), and SCI (Mawhinney et al., 2012; Thawer et al., 2013). Using this tool we show that microglia contact damaged axons early $(24 \mathrm{~h})$ after SCI 


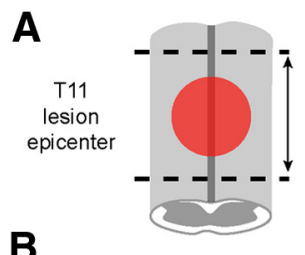

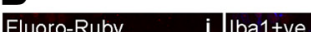
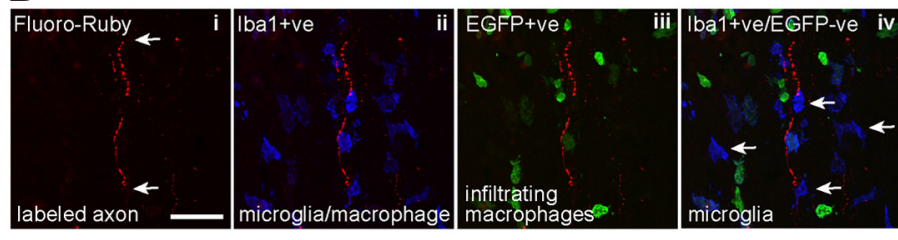

\section{C}
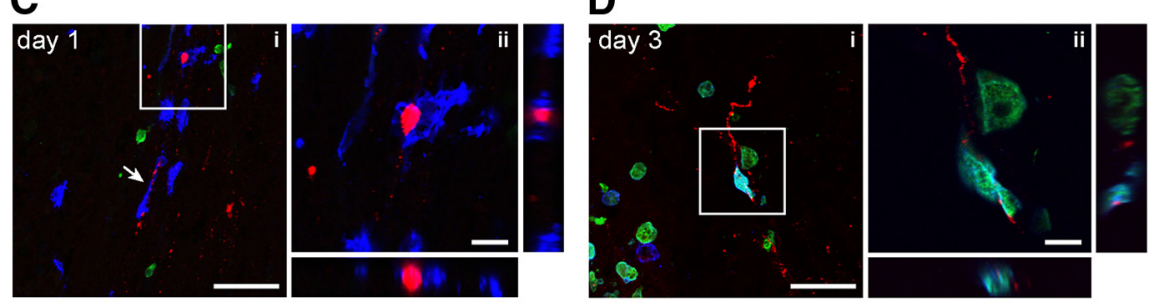

E
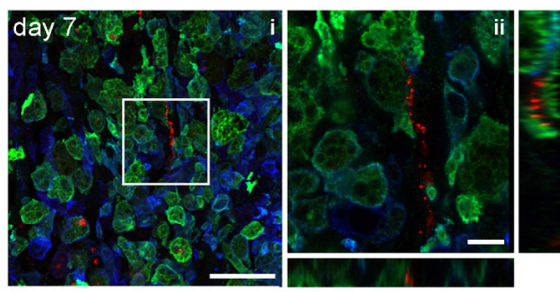

$\mathbf{F}$

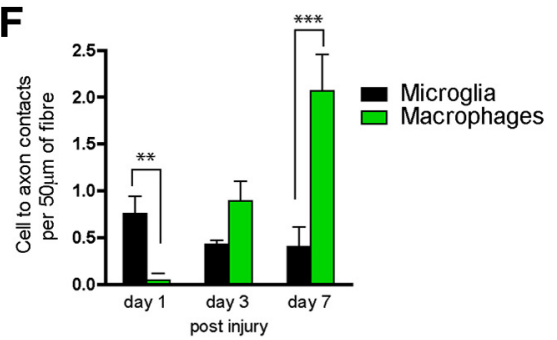

G
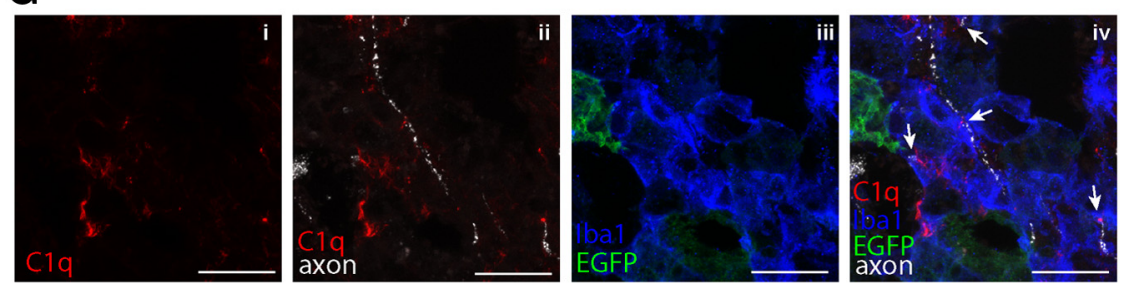

Figure 1. Timing of axonal contact and engulfment by microglia and infiltrating peripheral macrophages after SCl. $A$, Schematic shows the region at which longitudinal sections were analyzed for cellular contacts with labeled axons, i.e., at the lesion epicenter and areas immediately rostral and caudal (arrow bar $=\sim 4 \mathrm{~mm}$ ). Confocal images showing the strategy for identification of Fluoro-Ruby-labeled axons (Bi; arrows); Iba-1 staining, which labels microglia as well as peripherally derived macrophages (Bii); peripherally derived macrophages (EGFP+ve; Biii); and microglial cells (lba1+ve/EGFP-ve; arrows; $\boldsymbol{B i v}$ ). B $\boldsymbol{B}$, Shows complete $z$-stack image $(18 \mu \mathrm{m})$ and the $x-y, x-z$, and $y-z$ planes that illustrate Fluoro-Ruby-labeled axonal profile engulfed by microglia (EGFP-negative/lba1+) cells (arrows). Ci, A microglia appears to stretch along a labeled degenerating axon (arrow), and another microglia contacts and engulfs Fluoro-Ruby-labeled axon at $1 \mathrm{~d}$ after SCl. Area outlined in the square is shown at higher magnification in Cii. Di, Three days after SCI peripheral macrophages (EGFP + ve) as well as microglia (Iba1+ ve/EGFP-ve) contact FluoroRuby-labeled axons. Area outlined in the square is shown at higher magnification in Dii. Ei, Seven days after SCI macrophages of peripheral origin are the predominant phagocytic cell in contact with Fluoro-Ruby-labeled axons. Area outlined in the square is shown at higher magnification in Eii. $F$, Quantification of number of microglia and peripheral-derived macrophages in contact with Fluoro-Ruby-labeled axons 1, 3, and $7 \mathrm{~d}$ after $\mathrm{SCl}$. Average cell contact per $50 \mu \mathrm{m}$ labeled axon per mouse $(n=3-4)$. Values expressed as mean $\pm \mathrm{SEM} ;{ }^{* *} p<0.01,{ }^{* * *} p<0.001, n=4-5$. G, Shows quadruple fluorescence images of complement $\mathrm{C} 1 \mathrm{q}$ (i), (1q and Fluoro-Ruby-labeled axons (ii), Iba1 and EGFP (iii), and merged (iv), indicating presence of 1 1q in regions of damaged axons and microglia. Confocal $z$-stack images (12-18 $\mu \mathrm{m} ; \mathbf{B i}-\mathbf{i v}, \mathbf{C i}, \mathbf{D i}, \mathbf{E i}, \mathbf{G i}-\mathbf{i v})$ and the $x-y, x-z$, and $y-z$ planes showing triple labeling. Scale bars: $\boldsymbol{B}-\boldsymbol{E}$, large scale bars, $50 \mu \mathrm{m}$; small scale bars, $10 \mu \mathrm{m} ; \boldsymbol{G}, 20 \mu \mathrm{m}$.

and are the predominant cell type to contain phagocytic material at $3 \mathrm{~d}$, in vivo. Thereafter, infiltrating macrophages become the predominant cell in contact with degenerating axons and contain more phagocytic material. We also show that the phagocytic activity impacts the viability of macrophages but not microglia, as

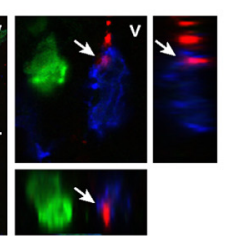

microglial cells appear to process phagocytic material more effectively than their infiltrating counterparts.

\section{Materials and Methods}

Animals. All procedures were approved by the Animal Care Committee of the Research Institute of the McGill University Health Centre and followed the guidelines of the Canadian Council on Animal Care and the ARRIVE guidelines for reporting animal research (Kilkenny et al., 2010). Female heterozygote lysEGFP-ki mice, 8 to 14 weeks of age, were used in all in vivo experiments (kindly provided by Dr. Thomas Graf and obtained from Dr. Steve Lacroix) and kept under a $12 \mathrm{~h}$ light/dark cycle with ad libitum access to food and water

Spinal cord contusion and neuronal labeling. Mice were deeply anesthetized by intraperitoneal injection of ketamine $(50 \mathrm{mg} / \mathrm{kg})$, xylazine $(5 \mathrm{mg} / \mathrm{kg})$, and acepromazine $(1 \mathrm{mg} / \mathrm{kg})$, and a moderate contusion injury $(50 \mathrm{kDa}$ force; 500-600 $\mu \mathrm{m}$ tissue displacement) was made at the T11 thoracic vertebral level using the Infinite Horizon Impactor device (Precision Scientific Instrumentation) as previously described (Ghasemlou et al., 2005). Animals were killed $24 \mathrm{~h}$ and 3, 7, 14, 28, and $42 \mathrm{~d}$ after SCI. For labeling of axons in the ascending dorsal column fibers, the sciatic nerve was exposed $7 \mathrm{~d}$ before SCI and $4 \mu \mathrm{l}$ of Fluoro-Ruby $(50 \mathrm{mg} / \mathrm{ml}$; Invitrogen) was injected into the nerve using a $50 \mu \mathrm{m}$ tip glass micropipette.

Immunofluorescence. Animals were perfused with $4 \%$ paraformaldehyde in $0.1 \mathrm{~m}$ PBS, $\mathrm{pH}$ 7.4. Spinal cord segments containing the lesion site were removed and processed for cryostat sectioning (14- $\mu \mathrm{m}$-thick longitudinal sections for axonal tracing and cross sections elsewhere). Immunofluorescence was performed using chicken anti-GFP (1:1000; Invitrogen), rabbit anti-Ibal (1:1000; Wako), rat antiCd11b (1:500; Serotec), rat anti-C1q (1:100; Abcam), and rabbit anti-Ki67 (1:500; Abcam) and detected using the appropriate secondary antibodies at 1:500; anti-chicken Alexa Fluor 488, anti-rabbit Alexa Fluor 647, anti-rat Alexa Fluor 568 (Invitrogen), and anti-rat Dylight-405 (Jackson ImmunoResearch). Antibody-labeled macrophages, Fluoro-Ruby-traced axons, and autofluorescent phagocytic material were visualized using a confocal laser scanning microscope (FluoView FV1000; Olympus) and prepared using FV10-ASW 3.0 software (Olympus). Autofluorescence of phagocytosed material was identified as accumulated punctuate structures with the $594 \mathrm{~nm}$ laser, as it was shown previously to emit strong light at wavelengths longer than $570 \mathrm{~nm}$ (Eichhoff et al., 2008).

Cell culture. Cultures of bone marrow-derived macrophages (BMDMs) were prepared from adult female C57BL/6 mice (6-8 weeks), as described previously (Longbrake et al., 2007). Mixed glial and purified microglia cultures were prepared from 2-d-old C57BL/6 mice, as described previously (Saura et al., 2003). Before use in experiments, cells were plated in 24-well plates at density $1 \times 10^{5}$ per well and cultured overnight. 
Myelin phagocytosis and flow cytometry. Cells were washed and incubated in culture medium (DMEM/F12, 10\% FBS, and 1\% MEM vitamin solution; Invitrogen) containing $50 \mu \mathrm{g} / \mathrm{ml}$ or $200 \mu \mathrm{g} / \mathrm{ml}$ bovine CNS myelin for $24 \mathrm{~h}$. At 24 and $48 \mathrm{~h}$, cells were harvested with $0.125 \%$ trypsin. After washing with PBS, cells were incubated with efluoro-780 viability dye (eBioscience) for $20 \mathrm{~min}$, blocked in 5\% BSA (Roche) and rat anti-FC-receptor antibody (1: 200; BD Bioscience), and labeled with the $\mathrm{mAb}$ PE-Cy7 anti-CD45 (BD Bioscience). Before data acquisition, cells were incubated with FITC-conjugated AnnexinV (1:100; eBioscience) in binding buffer ( $15 \mathrm{~mm} \mathrm{NaCl}, 0.5 \mathrm{~mm}$ $\mathrm{KCl}, 0.1 \mathrm{mM} \mathrm{MgCl}_{2}$, and $0.18 \mathrm{mM} \mathrm{CaCl}_{2}$ ) for 10 $\mathrm{min}$ at room temperature, washed in binding buffer and data acquired immediately on FACSCanto (Becton Dickinson), and analyzed using FlowJo software (TreeStar).

Immunocytochemistry. BMDMs and purified microglial cells were plated onto glass coverslips in 24-well plates at a density of $1 \times 10^{4}$ per coverslip. Myelin was fluorescently labeled by incubating $1 \mathrm{mg} / \mathrm{ml}$ of myelin with $12 \mu \mathrm{g} / \mathrm{ml}$ with Vibrant DiI-labeling solution (Invitrogen) at $37^{\circ} \mathrm{C}$ for $30 \mathrm{~min}$. Cells were incubated with DiI-myelin for $24 \mathrm{~h}$ and subsequently labeled with rat anti-CD11b (1:800; Serotec) and donkey anti-rat Alexa Fluor 488 (Invitrogen), and mounted with DAPI containing medium (Vector Laboratories).

TUNEL. Cross sections of the spinal cord were incubated with chicken anti-GFP and rabbit anti-Ibal, as above, before labeling of apoptotic cells with NeuroTACS II in situ apoptosis detection kit (Trevigen). Apoptosis was detected according to manufacturer's instructions but with replacement of Strep-HRP/DAB visualization procedure with a streptavidin Alexa Fluor 568 conjugate (Invitrogen). Quantification of TUNEL ${ }^{+}$cells was done from six cross sections of the spinal cord per mouse in the area adjacent to the epicenter of lesion ( $n=3-4$ mice per group).

Statistical analysis. Parametric data were analyzed using two-way ANOVA followed by Student's $t$ test with Bonferroni's correction.

\section{Results}

Microglia contact and engulf axons early after SCI, before the infiltration of blood-borne macrophages

To assess the timing and relative contribution of microglia and macrophages to the phagocytosis of degenerating axons after SCI, the neuronal tracer Fluoro-Ruby was injected into the sciatic nerve of lys-EGFP-ki mice $7 \mathrm{~d}$ before spinal cord contusion injury. This procedure labeled a population of axons in the ascending dorsal column, and allowed for the evaluation of microglia and macrophages in contact with damaged axons in this region. The schematic in Figure $1 A$ shows the region at which longitudinal sections were analyzed for microglia and macrophage contacts with Fluoro-Ruby-labeled degenerating axons, i.e., through the lesion epicenter, and areas immediately rostral and caudal to lesion (areas of Wallerian degeneration and axonal die-back). Figure $1 B$ shows the strategy used to identify microglia and macrophages in contact with traced axons. Fluoro-Ruby-positive axons were localized in the contused region of the spinal cord and cells in contact with these fibers were identified as peripherally derived macrophages $\left(\mathrm{EGFP}^{+}\right.$cells) or resident microglia (Iba1 ${ }^{+} /$EGFP-negative cells). It is important to note that the lysEGFP-ki lysozyme M promoter is also present in neutrophils (Faust et al., 2000). Therefore, to exclude neutrophils from the quantification, only cells larger than $15 \mu \mathrm{m}$ were considered for analysis.

Fluoro-Ruby-traced axons were often found within the contacting cell, indicating their engulfment. As expected, microglia were the predominant cell type contacting axons $1 \mathrm{~d}$ after SCI, with very few infiltrating macrophages present at this time point (Fig. 1C,F). After $3 \mathrm{~d}$, macrophages from the peripheral circulation begin to infiltrate the injured spinal cord and are found to contact with Fluoro-Ruby-traced axons at double the frequency as the resident microglia (Fig. $1 D, F$ ). Seven days after SCI, peripheral macrophages are the predominant cell type in contact with labeled axons (Fig. $1 E, F$ ).

Multiple receptor families may mediate macrophage interaction with axons after SCI, such as the Fc receptors, scavenger receptors, and complement receptors (Fu et al., 2014). Complement component $\mathrm{Clq}$ is one of the initiating proteins of the classical pathway of complement activation, which complexes with CD11b/CD18 (CR3/MAC-1) and has been shown to mediate microglial engulfment and remodeling of developing synapses (Schafer et al., 2012) and phagocytosis of apoptotic cells (Païdassi et al., 2008). With quadruple fluorescence staining, at day 3 and 7, after SCI we observed C1q immunolabeling localized to damaged axons (visualized by the discontinuous Fluoro-Ruby labeling) and the associated microglia (Iba1 ${ }^{+} /$EGFP-ve) and infiltrating macrophages (EGFP+ve; Fig. 1G). These results provide evidence that $\mathrm{C} 1 \mathrm{q}$ may contribute to the clearance of axons after SCI.

Phagocytosed material is present transiently in microglia but persists in peripheral macrophages

Figure $1 F$ shows the differential timing and relative number of cells contacting damaged axons after SCI, and suggests that these fibers are phagocytosed by both microglia and peripheral macro- 

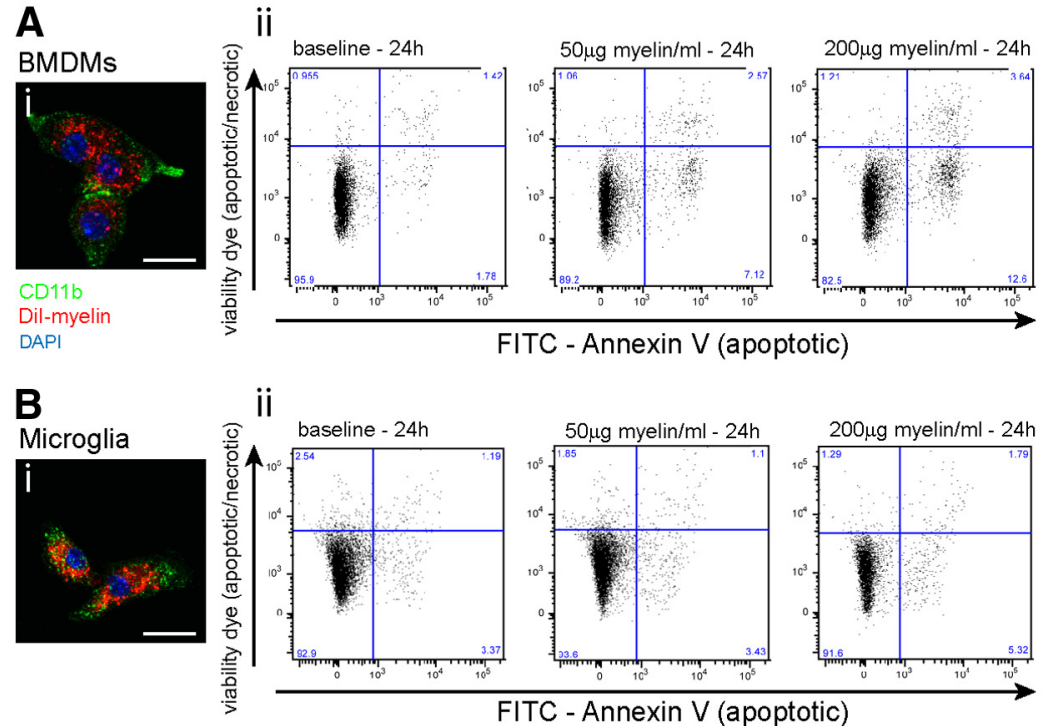

FlTC - Annexin $V$ (apoptotic)

FITC - Annexin V (apoptotic)
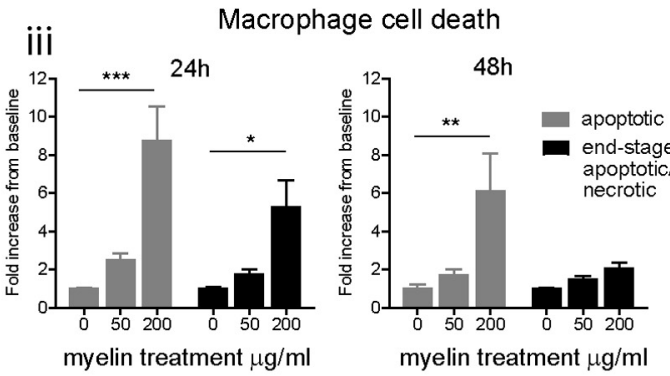

iii
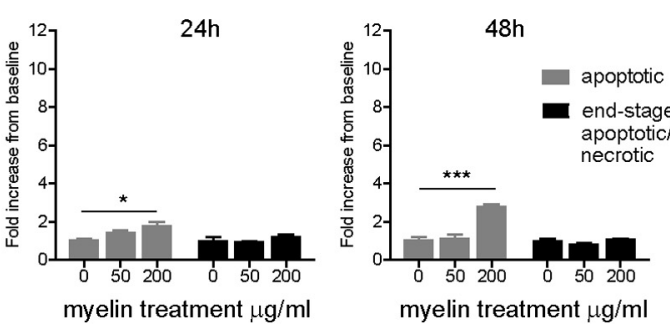

Figure 3. Peripheral macrophages are more susceptible than microglia to cell death after phagocytosis of myelin, in vitro. Fluorescent images showing BMDMs (Ai) and primary microglia (Bi) take up Dil-labeled myelin, in vitro. Aii, Bii, Representative FACS plots of CD45 ${ }^{+}$cells labeled for AnnexinV (apoptotic marker) and efluoro-780 (viability dye). Plots show level of apoptotic cell death (FITC-AnnexinV-positive, efluoro-780 viability dye positive; bottom right quadrant) and end-stage apoptosis/necrosis (efluoro-780 viability dye positive; top two quadrants) with increasing amounts of myelin added for $24 \mathrm{~h}$. Aiii, Peripheral-derived macrophages show significant increase in apoptosis after treatment with $200 \mu \mathrm{g} / \mathrm{ml}$ myelin (24 h, 8.7-fold and $48 \mathrm{~h}, 6.1$-fold). Biii, Primary microglia show much lower levels of apoptotic cell death in cultures treated with $200 \mu \mathrm{g} / \mathrm{ml}$ myelin $(24 \mathrm{~h}, 1.7$-fold and $48 \mathrm{~h}, 2.8$-fold). End-stage apoptosis/necrosis increased 5.3-fold in peripherally derived macrophages at $24 \mathrm{~h}\left(200 \mu \mathrm{g} / \mathrm{ml}\right.$ myelin), while necrotic cell death was not seen at either time point in primary microglia. Values expressed as mean \pm SEM; ${ }^{*} p<0.05,{ }^{* *} p<$ $0.01,{ }^{* * *} p<0.0001 . n=3-4$. Scale bar, $20 \mu \mathrm{m}$.

phages. To investigate further which cells are predominantly responsible for the clearance of cell and tissue debris, we used the inherent fluorescent properties of phagocytosed material, within the cells, to determine the relative contribution of each cell type to tissue clearance. Accumulated cell debris within cells, which has a composition likely akin to that of lipofuscins, emits a strong autofluorescence with a punctuate-like appearance at wavelengths longer than $570 \mathrm{~nm}$ (Brunk and Terman, 2002).

Cross sections of the spinal cord at the level of the contusion injury were assessed in regions immediately adjacent to the epicenter (Fig. 2G). Three days after SCI, despite peripheral macrophages outnumbering microglial cells in the region, $\sim 50 \%$ of the microglial cells in this area contained autofluorescent phagocytic material (the mean number of autofluorescent microglia/mean number of microglia $=6 / 13 ; n=4$ ), reflecting the role of microglia as the first phagocytic responder to tissue injury. At this time point only $12 \%$ of the infiltrating macrophages contain phagocytic material $(5 / 43 ; n=4 ; p<0.01$; Fig. $2 A, F)$, There was a small increase in the percentage of infiltrating macrophages containing autofluorescent material at day 7 to $19 \%(18 / 97 ; n=4$; Fig. $2 B)$, which then increased to its maximum of $\sim 47 \%(29 / 61$; $n=3$ ) at day 14 (Fig. 2C,F). Interestingly, this material was still seen in a high percentage of peripheral macrophages at day 28 $(\sim 39 \%, 25 / 65 ; n=5)$ and $42 \mathrm{~d}(\sim 30 \%, 12 / 42 ; n=4)$ after SCI (Fig. $2 D-F)$. In contrast, a very small percentage of microglia contained autofluorescent material at day $7(\sim 4 \%, 1 / 19 ; n=4)$, day $14(\sim 3 \%, 1 / 35 ; n=3)$, day $28(\sim 9 \%, 3 / 35 ; n=5)$, and day 42 $(\sim 2 \%, 1 / 44 ; n=4)$, indicating that they either successfully degrade the material or underwent cell death and were no longer present.

At day 14, 28, and 42, cells with weak EGFP fluorescence around the injury site were often seen to contain punctate autofluorescence, revealing accumulation of tissue debris within these cells. It is possible that these cells are no longer viable and have stopped producing EGFP (Fig. 2H). The half-life of nonenhanced GFP is $\sim 26 \mathrm{~h}$ in cultured cells (Corish and Tyler-Smith, 1999); therefore, EGFP protein will still be present within cells during the process of cell death, which may have occurred due to an overload of undegraded, phagocytosed material.

\section{Peripheral macrophages are more susceptible than microglia} to cell death after phagocytosis of myelin

To directly address whether macrophages of microglial origin are more susceptible to cell death after phagocytosis than macrophages of peripheral origin, cells were cultured in vitro with myelin and their phagocytic activity and viability were assessed. To confirm that myelin was phagocytosed to a similar extent by both primary microglia and BMDMs, these cells were incubated with DiI-labeled myelin for $24 \mathrm{~h}$, and myelin phagocytosis assayed by DiI fluorescence combined with immunofluorescence labeling for CD11b (Fig. 3Ai,Bi).

To investigate if cell death occurs after myelin phagocytosis, primary mixed glial cell cultures and BMDMs were harvested 24 and $48 \mathrm{~h}$ after incubation with unlabeled myelin (50 and 200 $\mu \mathrm{g} / \mathrm{ml}$ ), and assessed using flow cytometry. Live, apoptotic, and end-stage apoptotic/necrotic $\mathrm{CD} 45^{+}$macrophages and microglia were identified in the following manner: efluoro-780 viability dye -ve/AnnexinV-FITC -ve, live cells (Fig. 3Aii,Bii, bottom left quadrant); efluoro-780 viability dye -ve/AnnexinV-FITC +ve, apoptotic cells (Fig. 3Aii,Bii, bottom right quadrant); efluoro780 viability dye + ve, end-stage apoptotic/necrotic cells (Fig. $3 A i i, B i i$, top two quadrants). Our FACS analysis shows that there is a dose-dependent increase in apoptotic cell death at 24 and $48 \mathrm{~h}$ in peripherally derived macrophages, compared with baseline (nonphagocytosing cells). A significant increase in apoptotic death is seen with $200 \mu \mathrm{g} / \mathrm{ml}$ myelin at $24 \mathrm{~h}(8.7$-fold, $p<0.0001)$ and $48 \mathrm{~h}$ (6.1-fold, $p<0.01$; Fig. 3Aiii). Apoptotic cell death also occurred in cultures of primary microglia treated with $200 \mu \mathrm{g} / \mathrm{ml}$ 

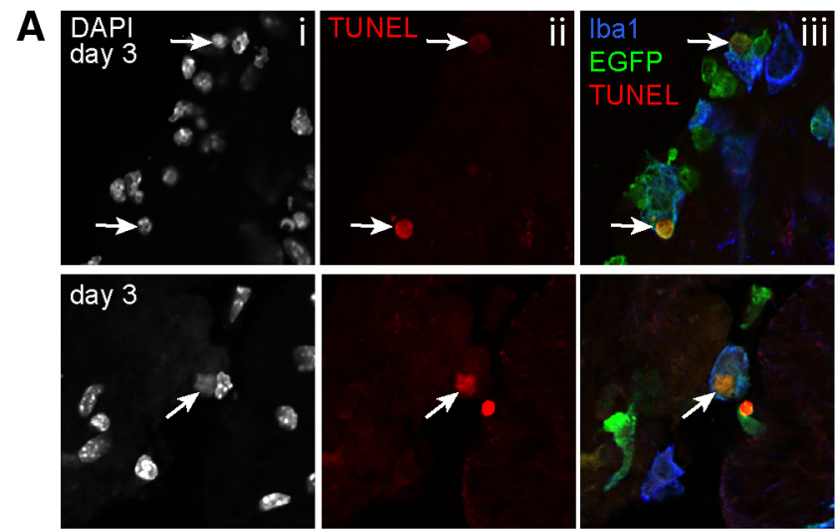

\section{B}
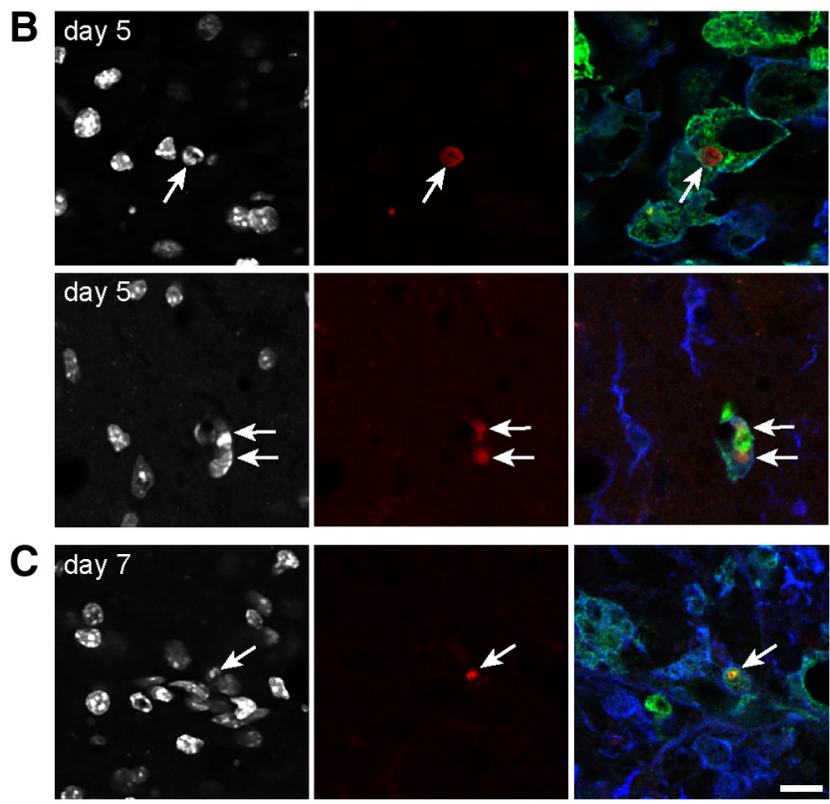

Figure 4. Infiltrating peripherally derived macrophages are more susceptible to apoptosis than microglia after $\mathbf{S C I}$. $\boldsymbol{A}-\boldsymbol{C}$, Single-plane confocal images showing TUNEL, Iba1, EGFP, and DAPI labeling at 3, 5, and $7 \mathrm{~d}$ after SCI. Ai-Ci, Show DAPI-positive nuclei. Aii-Cii, Show TUNELpositive nuclei. Aiii-Ciii, Merged Iba1, EGFP, and TUNEL. Note that the TUNEL-positive apoptotic cells (arrows) are also EGFP ${ }^{+}$(Aiii-Ciii), indicating that they are peripherally derived macrophages. Scale bar, $10 \mu \mathrm{m}$.

myelin, but to a much lesser extent at $24 \mathrm{~h}(1.7$-fold, $p<0.05)$ and $48 \mathrm{~h}$ (2.8-fold, $p<0.0001$; Fig. 3Biii). End-stage apoptosis/necrosis also occurred in peripherally derived macrophages $24 \mathrm{~h}$ after incubation with $200 \mu \mathrm{g} / \mathrm{ml}$ myelin (5.3-fold, $p<0.05$ ); however, end-stage apoptosis/necrosis was not seen at either time point in primary microglia. A total of $\sim 17 \%$ of the peripheral macrophages undergo cell death (apoptotic and necrotic) at $24 \mathrm{~h}$ when incubated with $200 \mu \mathrm{g} / \mathrm{ml}$ myelin, and there appears to be concentration-dependent effect at $50 \mu \mathrm{g} / \mathrm{ml}$ myelin. Together, these results suggest that peripheral macrophages are more susceptible to cell death after myelin phagocytosis than microglia.

\section{Infiltrating macrophages are more susceptible than microglia} to apoptosis after SCI

As peripherally derived macrophages are more sensitive to cell death than primary microglia after the phagocytosis of myelin in vitro, we used the lys-EGFP-ki mouse to investigate whether the same phenomenon occurred in vivo, after SCI. TUNEL was used to identify DNA fragmentation in apoptotic cells at $24 \mathrm{~h}$ and 3,5 , and $7 \mathrm{~d}$ after spinal cord contusion injury. Despite a relatively low
A
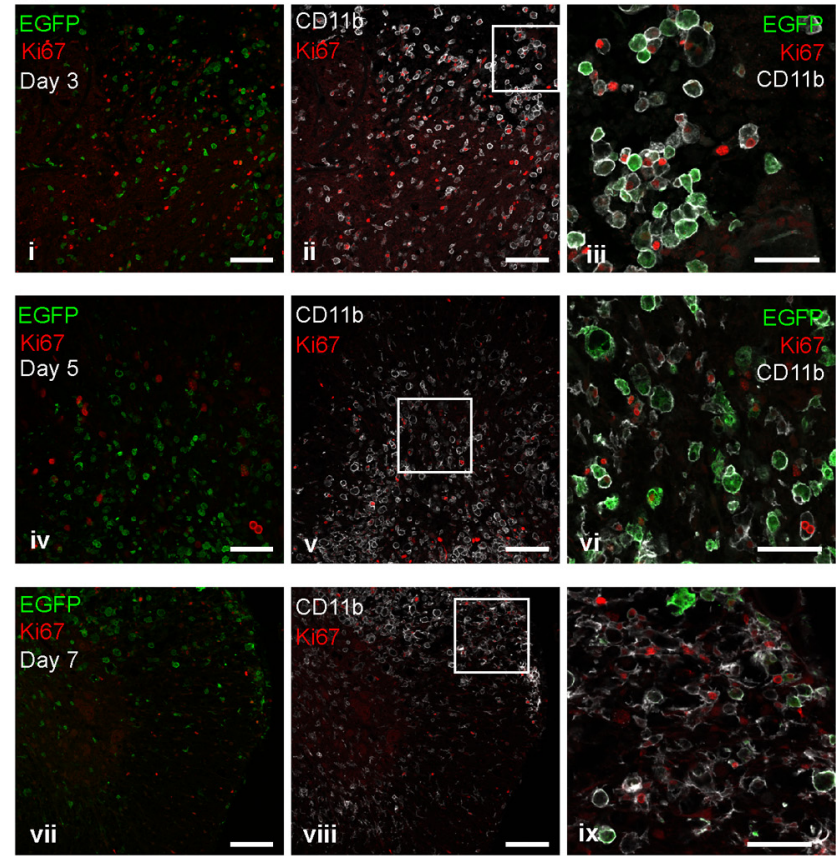

B

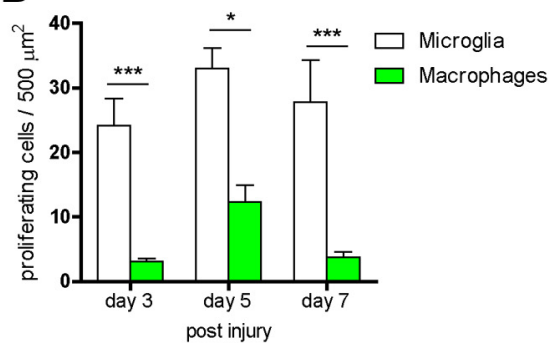

Figure 5. Microglial cells proliferate in greater numbers than infiltrating macrophages in $\mathrm{SCl}$. A, Representative confocal images of proliferation marker $\mathrm{Ki} 67^{+}$nuclei, infiltrating macrophages (EGFP $\left.{ }^{+}\right)$, and microglia $\left(\mathrm{CD}_{11 \mathrm{~b}^{+}} / \mathrm{EGFP}^{-}\right)$at 3,5 , and $7 \mathrm{~d}$ after SCl. Images were taken at the level of the lesion. Single-plane confocal fluorescent images of Ki67 and EGFP are shown on the left (i, iv, vii) and Ki67 and lba 1 are shown in the middle (ii, $\boldsymbol{v}$, vii). Areas outlined in the squares are merged and shown at higher magnification on the right (iii, vi, ix). Ki67positive nuclei were rarely localized to $\mathrm{EGFP}^{+}$macrophages 3,5 , and $7 \mathrm{~d}$ after $\mathrm{SCI}(\boldsymbol{i}$, iv, vii). $\boldsymbol{B}$, Significantly more CD11b + ve/EGFP-ve microglia than infiltrating macrophages were Ki67 positive at 3,5 , and $7 \mathrm{~d}$ after $\mathrm{SCl}$. Values expressed as mean $\pm \mathrm{SEM} ;{ }^{*} p<0.05,{ }^{* * *} p<0.0001$. $n=3-6$. Scale bars: small scale bars, $100 \mu \mathrm{m}$; large scale bars, $50 \mu \mathrm{m}$.

number of TUNEL-positive macrophages in the injured spinal cord, all the TUNEL-positive cells were macrophages of peripheral origin $\left(\mathrm{EGFP}^{+}\right)$at day $3\left(1.98 / 500 \mu \mathrm{m}^{2}, n=4\right)$ and at 5 $\left(1.64 / 500 \mu \mathrm{m}^{2}, n=3\right)$ and $7 \mathrm{~d}\left(2.46 / 500 \mu \mathrm{m}^{2}, n=3\right)$ after SCI (Fig. 4). The number of apoptotic cells does not appear to increase over time, but are macrophages of peripheral origin, providing further evidence that these cells are more susceptible than microglia to phagocytosis-induced cell death after SCI.

\section{Microglial cells proliferate in greater numbers than} infiltrating macrophages at the site of contusion injury Thus far we have shown that microglia contribute to the early phagocytic response after SCI and are not as susceptible to cell death compared with infiltrating macrophages. The marked decrease in the number of microglia with phagocytic material beyond $3 \mathrm{~d}$ after SCI suggests that these cells are able to more efficiently handle and process phagocytosed cell debris than peripheral macrophages. We hypothesized that this might be due, in part, to 
a higher proliferative capacity of microglia over infiltrating macrophages in the spinal cord (Ajami et al., 2007). To assess this, we used Ki67 immunofluorescence labeling to detect proliferating cells. The number of $\mathrm{Ki}^{+} 7^{+}$microglia and infiltrating macrophages were quantified in the same region from which cells were quantified for phagocytic load (Fig. $2 G$ ), at day 3, 5, and 7 after SCI. Ki67 ${ }^{+}$cells were found throughout the sections at the level of contusion but were rarely localized to $\mathrm{EGFP}^{+}$macrophages 3 and $7 \mathrm{~d}$ after SCI (Fig. 5Ai,Avii). Significantly more $\mathrm{Ibal}^{+} /$ EGFP $^{-}$microglia than infiltrating macrophages were $\mathrm{Ki}^{+}{ }^{+}$at 3 $(p>0.001), 5(p>0.05)$, and $7 \mathrm{~d}(p>0.001$; Fig. $5 B)$ after SCI (Fig. 5Aiii,vi,ix). These results indicate up to sevenfold greater proliferation of microglia as compared with infiltrating macrophages in an area of robust phagocytic activity. It is possible therefore that proliferation of microglia in the injured spinal cord would reduce the phagocytic load with each cell division and render them less susceptible to cellular stress and death (Brunk and Terman, 2002).

\section{Discussion}

Inflammation plays a prominent role in the aftermath of traumatic CNS injury. Physical damage to resident cells and bleeding into spinal cord tissue causes a profound inflammatory reaction resulting in a tremendous infiltration of macrophages to the spinal cord (Mawhinney et al., 2012). Their primary role is to remove tissue and cellular debris, thus enabling the resolution of inflammation and tissue repair (Serhan et al., 2007). However, a prolonged or excessive inflammatory response can be detrimental to recovery (David and Kroner, 2011). These roles are also assumed to be performed by microglia; however, until recently, it has been difficult to separate these two cell populations in tissue sections, and the extent of the microglial contribution to phagocytosis of degenerating tissue in vivo, after SCI, was not known. Using lys-EGFP-ki mice and Fluoro-Ruby labeling of axons, we show that microglia contact and appear to engulf labeled damaged axons early after SCI. Other work using triple transgenic Thy1-CFP/LysM-GFP/CD11c-EYFP reporter mice showed limited involvement of resident microglial cells in the phagocytosis of degenerating axons after microlesions of the spinal cord elicited by a $500 \mu \mathrm{m}$ deep insertion of a $26 \mathrm{G}$ needle (Fenrich et al., 2013). The lack of microglial involvement in this study may be explained by the relatively low-grade inflammatory response caused by the microlesion, as compared with the prominent inflammatory response induced by spinal cord contusion injury, leading to a more robust and widespread activation of microglia. In support of this, studies in other CNS models of disease with a large inflammatory component, such as EAE, suggest that microglial aggregation around sites of blood-brain barrier breakdown mediates axonal damage (Davalos et al., 2012). Our studies suggest that microglia and, to a much larger extent, macrophages from the periphery phagocytose damaged tissue after SCI.

Cellular debris once engulfed by phagocytic cells was found to persist within peripheral-derived macrophages for up to $42 \mathrm{~d}$, but, unexpectedly, was not present in microglia after $3 \mathrm{~d}$. Therefore, microglia were either no longer viable, and thus unidentifiable, or they were able to degrade the phagocytic material more efficiently than infiltrating macrophages. Our in vitro experiments indicated that peripheral macrophages were more susceptible to cell death than primary microglia after myelin phagocytosis, suggesting that microglial cells may be better equipped to process and degrade the phagocytosed material. In addition, apoptosis was seen almost exclusively in infiltrating macrophages, in vivo. Stress of undegraded material upon the cell is often seen in aged neuronal cell bodies, where oxidatively modified protein and lipid degradation products, known as lipofuscin, accumulate (Brunk and Terman, 2002). Accumulation of lipofuscin sensitizes cells to oxidative stress-induced lysosomal breach and apoptosis, probably via release of lysosomal enzymes and other free radical-generating material in lipofuscin (Brunk and Terman, 2002). We found that at late time points after SCI $(14,28$, and $42 \mathrm{~d})$, autofluorescent phagocytic material is often seen in what appeared to be dying $\mathrm{EGFP}^{+}$cells, i.e., in peripheral macrophages. We also provide evidence that microglial proliferation is about $\sim 7$-fold greater than peripheral-derived macrophages. It is possible that increased cell division would reduce the phagocytic load in these cells and thus make them less susceptible to cell death as compared with peripheral-derived macrophages. Additionally, other factors affecting intracellular breakdown of material, such as lysosomal activity, may differ in microglia and infiltrating macrophages and contribute to differences in their viability after SCI.

Unlike the kinetics of macrophage influx into the spinal cord after injury, there is a paucity of information regarding their efflux and/or death during resolution of inflammation, which is prolonged in SCI (Prüss et al., 2011). Evidence that infiltrating macrophages become resident CNS cells after injury has been shown (Simard et al., 2006), and contested (Ajami et al., 2011). Whether these cells remain in the CNS, or successfully efflux, their death in situ, accompanied by the release a multitude of harmful agents (such as active proteases and decondensed DNA), is likely to be detrimental to SCI outcome. Our work suggests that the ontogentically distinct, CNS macrophage population (microglia) plays a major role in the early response to SCI by phagocytosing damaged and degenerating tissue, processing phagocytic material efficiently, and remaining viable to continue their role. Macrophages of peripheral origin are less capable of handling the CNS debris, and their death, in situ, may contribute to secondary damage and poor outcome after CNS injury.

\section{References}

Ajami B, Bennett JL, Krieger C, Tetzlaff W, Rossi FM (2007) Local selfrenewal can sustain CNS microglia maintenance and function throughout adult life. Nat Neurosci 10:1538-1543. CrossRef Medline

Ajami B, Bennett JL, Krieger C, McNagny KM, Rossi FM (2011) Infiltrating monocytes trigger EAE progression, but do not contribute to the resident microglia pool. Nat Neurosci 14:1142-1149. CrossRef Medline

Brunk UT, Terman A (2002) Lipofuscin: mechanisms of age-related accumulation and influence on cell function. Free Radic Biol Med 33:611619. CrossRef Medline

Corish P, Tyler-Smith C (1999) Attenuation of green fluorescent protein halflife in mammalian cells. Protein Eng 12:1035-1040. CrossRef Medline

Davalos D, Grutzendler J, Yang G, Kim J, Zuo Y, Jung S, Littman DR, Dustin ML, Gan WB (2005) ATP mediates rapid microglial response to local brain injury in vivo. Nat Neurosci 8:752-758 CrossRef Medline

Davalos D, Ryu JK, Merlini M, Baeten KM, Le Moan N, Petersen MA, Deerinck TJ, Smirnoff DS, Bedard C, Hakozaki H, Gonias Murray S, Ling JB, Lassmann H, Degen JL, Ellisman MH, Akassoglou K (2012) Fibrinogeninduced perivascular microglial clustering is required for the development of axonal damage in neuroinflammation. Nat Commun 3:1227. CrossRef Medline

David S, Kroner A, David S (2011) Repertoire of microglial and macrophage responses after spinal cord injury. Nat Rev Neurosci 12:388-399. CrossRef Medline

Eichhoff G, Busche MA, Garaschuk O (2008) In vivo calcium imaging of the aging and diseased brain. Eur J Nucl Med Mol Imaging 35[Supp 1]:S99_ S106. CrossRef Medline

Faust N, Varas F, Kelly LM, Heck S, Graf T (2000) Insertion of enhanced green fluorescent protein into the lysozyme gene creates mice with green fluorescent granulocytes and macrophages. Blood 96:719-726. Medline Fenrich KK, Weber P, Rougon G, Debarbieux F (2013) Long and short term 
intravital imaging reveals differential spatiotemporal recruitment and function of myelomonocytic cells after spinal cord injury. J Physiol 591: 4895-4902. CrossRef Medline

Fu R, Shen Q, Xu P, Luo J, Tang Y (2014) Phagocytosis of microglia in the central nervous system diseases. Mol Neurobiol. Advance online publication. doi: 10.1007/s12035-013-8620-6. CrossRef Medline

Gensel JC, Kigerl KA, Mandrekar-Colucci SS, Gaudet AD, Popovich PG (2012) Achieving CNS axon regeneration by manipulating convergent neuro-immune signaling. Cell Tissue Res 349:201-213. CrossRef Medline

Ghasemlou N, Kerr BJ, David S (2005) Tissue displacement and impact force are important contributors to outcome after spinal cord contusion injury. Exp Neurol 196:9-17. CrossRef Medline

Ginhoux F, Greter M, Leboeuf M, Nandi S, See P, Gokhan S, Mehler MF, Conway SJ, Ng LG, Stanley ER, Samokhvalov IM, Merad M (2010) Fate mapping analysis reveals that adult microglia derive from primitive macrophages. Science 330:841-845. CrossRef Medline

Howe CL, LaFrance-Corey RG, Sundsbak RS, LaFrance SJ (2012) Inflammatory monocytes damage the hippocampus during acute picornavirus infection of the brain. J Neuroinflammation 9:50. CrossRef Medline

Kilkenny C, Browne WJ, Cuthill IC, Emerson M, Altman DG (2010) Improving bioscience research reporting: the ARRIVE Guidelines for reporting animal research. PLoS Biol 8:e1000412. CrossRef Medline

Longbrake EE, Lai W, Ankeny DP, Popovich PG (2007) Characterization and modeling of monocyte-derived macrophages after spinal cord injury. J Neurochem 102:1083-1094. CrossRef Medline

Mawhinney LA, Thawer SG, Lu WY, Rooijen Nv, Weaver LC, Brown A, Dekaban GA (2012) Differential detection and distribution of microglial and hematogenous macrophage populations in the injured spinal cord of lys-EGFP-ki transgenic mice. J Neuropathol Exp Neurol 71:180197. CrossRef Medline

Nimmerjahn A, Kirchhoff F, Helmchen F (2005) Resting microglial cells are highly dynamic surveillants of brain parenchyma in vivo. Science 308: 1314-1318. CrossRef Medline

Oweida AJ, Dunn EA, Karlik SJ, Dekaban GA, Foster PJ (2007) Iron-oxide labeling of hematogenous macrophages in a model of experimental autoimmune encephalomyelitis and the contribution to signal loss in fast imaging employing steady state acquisition (FIESTA) images. J Magn Reson Imaging 26:144-151. CrossRef Medline

Païdassi H, Tacnet-Delorme P, Garlatti V, Darnault C, Ghebrehiwet B, Gaboriaud C, Arlaud GJ, Frachet P (2008) Clq binds phosphatidylserine and likely acts as a multiligand-bridging molecule in apoptotic cell recognition. J Immunol 180:2329-2338. Medline

Popovich PG, Hickey WF (2001) Bone marrow chimeric rats reveal the unique distribution of resident and recruited macrophages in the contused rat spinal cord. J Neuropathol Exp Neurol 60:676-685. Medline

Prüss H, Kopp MA, Brommer B, Gatzemeier N, Laginha I, Dirnagl U, Schwab JM (2011) Non-resolving aspects of acute inflammation after spinal cord injury (SCI): indices and resolution plateau. Brain Pathol 21:652660. CrossRef Medline

Saura J, Tusell JM, Serratosa J (2003) High-yield isolation of murine microglia by mild trypsinization. Glia 44:183-189. CrossRef Medline

Schafer DP, Lehrman EK, Kautzman AG, Koyama R, Mardinly AR, Yamasaki R, Ransohoff RM, Greenberg ME, Barres BA, Stevens B (2012) Microglia sculpt postnatal neural circuits in an activity and complementdependent manner. Neuron 74:691-705. CrossRef Medline

Serhan CN, Brain SD, Buckley CD, Gilroy DW, Haslett C, O'Neill LA, Perretti M, Rossi AG, Wallace JL (2007) Resolution of inflammation: state of the art, definitions and terms. FASEB J 21:325-332. CrossRef Medline

Shechter R, Schwartz M (2013) Harnessing monocyte-derived macrophages to control central nervous system pathologies: no longer 'if but 'how'. J Pathol 229:332-346. CrossRef Medline

Simard AR, Soulet D, Gowing G, Julien JP, Rivest S (2006) Bone marrowderived microglia play a critical role in restricting senile plaque formation in Alzheimer's disease. Neuron 49:489-502. CrossRef Medline

Thawer SG, Mawhinney L, Chadwick K, de Chickera SN, Weaver LC, Brown A, Dekaban GA (2013) Temporal changes in monocyte and macrophage subsets and microglial macrophages following spinal cord injury in the lys-egfp-ki mouse model. J Neuroimmunol 261:7-20. CrossRef Medline

Yong VW, Rivest S (2009) Taking advantage of the systemic immune system to cure brain diseases. Neuron 64:55-60. CrossRef Medline 